\title{
Das pressões às ousadias: o confronto entre a descentralização tutelada e a gestão em rede no SUS*
}

Leonardo Trevisan**

Su MÁRIO: 1. Introdução; 2. Os limites do Estado "anêmico"; 3. A questão da universalidade; 4. Outras formas de gerência do ambiente SUS; 5. Limites operacionais do conceito de rede; 6 . Fluxos de recursos e novos padrões operacionais.

SUMMARY: 1 . Introduction; 2 . The limitations of the 'anemic' state; 3 . The universality issue; 4 . Other forms of management of the SUS environment; 5. Operational limitations of the network concept; 6. Flow of funds and new operational patterns.

Palavras-Chave: SUS; reforma do Estado; gestão pública; políticas públicas; descentralização; reforma do setor de saúde.

KEY WORDS: SUS; state reform; public management; public policies; decentralization; health sector reform.

Vista no tempo, a implantação do SUS vem enfrentando descompassos gerenciais. Primeiro, as pressões, sempre maiores, por reforma do Estado que minimalize custos, afetam a proposta de atendimento universal do sistema. Depois, a difícil convivência entre o princípio da descentralização com o conceito de rede, aqui entendida não só como ligação entre esferas diferenciadas de gestão, mas como o modo pelo qual o acesso a um direito é exercido em rede, desde o planejamento. Por outro lado, decisões operacionais sobre a saúde foram descentralizadas, mas o processo de repasse das verbas para efetivar tais decisões não foi. No aspecto admi-

\footnotetext{
* Artigo recebido em ago. 2004 e aceito em mar. 2006.

** Professor titular da PUC-São Paulo, doutor em ciência política pela USP, com pós-doutorado em economia pela University of Warnick (Inglaterra) e em ciência política pela University of London (Inglaterra). Endereço: Rua Morgado Mateus, 482, ap. 91 - CEP 04015-051 São Paulo, SP, Brasil. E-mail: 1trevisan@espm.br.
} 
nistrativo, a descentralização da gestão de saúde sofreu solução de continuidade com a edição da Norma Operacional de Assistência à Saúde no 01/2001. No aspecto gerencial, a implantação do conceito de rede, a arma mais eficiente para enfrentar a verticalização de estruturas decisórias, enfrenta "gargalos" operacionais e financeiros (implantação do "cartão eletrônico") que impedem os atores das diferentes organizações de falarem a mesma "linguagem", o meio mais eficaz para gerar "vínculos" interorganizacionais.

From pressure to boldness: the conflict between decentralization and network management in SUS

Taken into perspective, the implementation of the Unified Health System (SUS) has been facing managerial problems. First, because the increasing pressures for state reforms that will minimize costs affect the system's concept of universal care. Second, it is hard to balance the decentralization principle with the network concept, understood here not only as the link between different management spheres but also as how one can exercise his or her right in a network, from the planning stage on. On the other hand, operational decisions on healthcare were decentralized but the fund flow was not. Administratively speaking, the decentralization of healthcare management suffered an interruption when the Healthcare Operational Guideline n. 01/2001 came into effect. From the managerial standpoint, the introduction of the network concept, the strongest weapon against verticalization of the decision making process, faces operational and financial constraints (the implementation of electronic tokens) that keep the different organizations from 'speaking the same language', which is the most effective way to create inter-organizational 'bonds'.

\section{Introdução}

A Constituição de 1988 estabeleceu, corrigindo histórica distorção da sociedade brasileira, que o direito à saúde era conquista universal, sem exclusões. $O$ registro no mercado formal de trabalho, por exemplo, não seria mais fonte de discriminação para o pleno exercício desse direito. Essa determinação constitucional, que permitiria a efetiva implantação do Sistema Único de Saúde uma aspiração de décadas de boa parte dos profissionais de saúde pública foi construída a partir de duas garantias básicas: universalidade e descentralização. O exercício da eqüidade, apesar de sua importância, foi superado num primeiro momento pelas exigências da efetiva implementação da universalidade no sistema. 
Após 1988 irromperam dois novos atores no cenário da saúde pública brasileira: as dezenas de milhões de brasileiros pobres, que passavam a ter garantia constitucional para enfrentar a doença e o fortalecimento do chamado poder local na estrutura constitucional do país. Parte considerável da certeza de que o SUS "sairia do papel", da fria letra da lei e seria o marco divisório que representou na história do sistema de gestão de saúde pública no Brasil, se formou porque esses dois elementos essenciais - o princípio do atendimento universal e a descentralização - conquistaram espaço no processo decisório da saúde pública.

Observada na distância do tempo, de quase uma década e meia, a implantação do SUS enfrenta dois descompassos gerenciais que sinalizam algumas incompatibilidades que, se não inviabilizam, ameaçam a estratégia de eficiência do ambiente SUS. O primeiro é a distância entre a imposição de uma política pública de saúde de cunho universalista e as pressões, sempre maiores, por uma reforma do Estado, que minimalize custos como princípio norteador (Minayo, 2001). O segundo é a difícil convivência do princípio da descentralização com a crescente implementação da idéia de rede, aqui entendida não apenas como ligação entre esferas diferenciadas de gestão (sejam públicas ou privadas), mas como o modo pelo qual o acesso a um direito (ou a um conhecimento) é exercido em rede "desde o planejamento, oferta e realização desse acesso (McGuire, 2002). O princípio de "rede", essência do SUS, precisa ser complementar e não contraposto ao de descentralização, como algumas vezes tem ocorrido.

Os dois descompassos gerenciais talvez tenham o mesmo vício de origem: a exemplar ingenuidade de que as resistências para a implantação do SUS eram exógenas ao sistema e deveriam, portanto, ser resolvidas em instâncias externas, a primeira delas a da elaboração de leis e portarias. Ao longo do tempo foi possível identificar que a maior resistência ao modelo é endógena à administração pública e está nas formas operacionais do sistema, no modelo de gestão e, principalmente, no fluxo de recursos. O campo de batalha decisivo para a mudança de mentalidade na saúde pública está contido no que chamamos de três arcos de poder que existem no SUS: no cotidiano operacional, na definição da instância administrativa responsável pela elaboração de normas e, por último, na exata percepção de a quem pertence o poder real - quem é o "dono" - da decisão quanto ao repasse de recursos para a gestão descentralizada de saúde no Brasil.

\section{Os limites do Estado "anêmico"}

Os três arcos de poder do sistema de saúde pública acima mencionados obedecem ao princípio norteador expresso pelo artigo 198 da Constituição Federal, 
segundo o qual, as ações e serviços públicos de saúde integram uma "rede regionalizada e hierarquizada" e constituem um sistema único obediente a três diretrizes, expressas em três incisos do artigo. O primeiro deles é a descentralização "com direção única em cada esfera de governo"; depois, o atendimento integral "com prioridade para as atividades preventivas, sem prejuízo dos serviços assistenciais"; e, por último, a Constituição, que determina, sem especificações, a "participação da comunidade".

Assim, a determinação constitucional engendra complexa teia de interesses, que está na origem do primeiro dos descompassos, mencionados na introdução deste artigo: o SUS deve ser "universal" mas o Estado deve ser "mínimo". O descompasso relativo à gestão em rede do SUS também está vinculado à forma de expressão legal do sistema, mas vamos começar tratando da pretensão constitucional de cuidar de modo universal e descentralizado da saúde de todos por um Estado pensado para viver em constante "anemia induzida".

O conceito de descentralização em saúde, desde os debates dos anos 1970, sempre foi acompanhado da idéia de municipalização. Dados do Ministério da Saúde revelam que dos 5.506 municípios brasileiros, 5.451 - 98,8\% - estavam habilitados à gestão municipalizada de saúde em dezembro de 2000 (Ministério da Saúde, 2000). Portanto, quanto ao estrito cumprimento das normas legais, a municipalização da saúde estaria "pronta" e com ela a descentralização estaria avançando celeremente. Não há discussão quanto à necessidade de descentralizar a ação do SUS, mas é incontestável que os resultados reais desse processo de municipalização permanecem objeto de irreconciliáveis discordâncias. Silvio Fernandes da Silva (2001) elaborou clara distinção entre os que são contra a municipalização na forma em que está sendo implementada por considerar "radical" essa implantação e os que, por outro lado, consideram totalmente insatisfatória e insuficiente a "autonomia local" já conquistada.

É importante acompanhar os argumentos de cada corrente, desde as suas propostas iniciais, ainda nos anos 1990. Para os que consideram excessiva a municipalização da saúde já alcançada é obrigatório redefinir os "papéis" de estados, municípios e União na descentralização da saúde. O principal argumento é que a "excessiva polarização" entre União e municípios acaba por proteger demais a instância municipal, em detrimento das instâncias estaduais e regionais de gestão (Mendes, 1998). Como a União mantém o controle do repasse de recursos o choque é inevitável, com sérios prejuízos ao usuário do sistema.

Os argumentos a favor da municipalização com a maior autonomia possível criticam as normas federais que operacionalizam a descentralização por todos os limites que impõem ao exercício do poder local e, principalmente, a pretensão de que políticas públicas de saúde possam ser implementadas "sem 
a participação dos atores locais" (Bueno e Mehry, 1998). A conhecida observação de que as normas ditadas "de cima para baixo" têm execução difícil e avaliação de resultados muito complicada é a base dessa argumentação.

Tanto a análise favorável como a contrária à autonomia local, privilegiam o poder de decisão do Estado, seja ele federal ou municipal, sem discutir a efetiva capacidade de "impor vontade" de tal poder. A fragilidade desse poder não é distinta, seja no âmbito federal, seja na esfera local. Por exemplo, a cidade de São Paulo é o sexto orçamento da República. Teoricamente, os poderes de fiscalização do estado e do município nessa capital são significativos. Porém, o fato real é que 2,7 milhões dos 5,6 milhões de carros (46,8\%) cadastrados na capital paulista são "fantasmas", isto é, circulam em situação irregular sem qualquer licenciamento, sem quitação de impostos ou multas. Os dados do Departamento Estadual de Trânsito do Estado de São Paulo revelam que 41,6\% dos veículos irregulares estão nessa situação há mais de cinco anos (Diamante, 2004). A prefeitura, que tem participação no imposto estadual de licenciamento dos veículos e recebe integralmente os recursos arrecadados nas multas de trânsito, simplesmente, não consegue "efetuar" esse poder de Estado.

A instância da administração local — que na cidade mais rica do país não consegue fazer com que a metade dos automóveis circule pagando os impostos e multas devidas - recebeu, com o processo de municipalização da saúde, inerente às determinações constitucionais de 1988, um significativo conjunto de novas responsabilidades. A Lei Orgânica da Saúde nº 8.080, de 19 de setembro de 1990, definiu nos seguintes termos a competência dos municípios no setor de saúde:

Art. 18: À direção municipal do Sistema Único de Saúde — SUS — compete: I - planejar, organizar, controlar e avaliar as ações e serviços de saúde e gerir e executar os serviços públicos de saúde;

II - participar do planejamento, programação e organização da rede regionalizada e hierarquizada do Sistema Único de Saúde — SUS, em articulação com sua direção estadual;

III - participar da execução, controle e avaliação das ações referentes às condições e ambientes de trabalho;

IV - executar serviços:

a) de vigilância epidemiológica;

b) de vigilância sanitária;

c) de alimentação e nutrição;

d) de saneamento básico;

e) de saúde do trabalhador;

V - dar execução, no âmbito municipal, à política de insumos e equipamentos para a saúde; 


\begin{abstract}
VI - colaborar na fiscalização das agressões ao meio ambiente que tenham repercussão sobre a saúde humana e atuar junto aos órgãos municipais, estaduais e federais componentes, para controlá-las;

VII - formar consórcios administrativos intermunicipais;

VIII - gerir laboratórios públicos de saúde e hemocentros;

IX - colaborar com a União e os Estados na execução da vigilância sanitária de portos, aeroportos e fronteiras;

$\mathrm{X}$ - observado o disposto no artigo 26 desta Lei, celebrar contratos e convênios com entidades prestadoras de serviços privados de saúde, bem como controlar e avaliar sua execução;

XI - controlar e fiscalizar os procedimentos dos serviços privados de saúde; XII - normatizar complementarmente as ações e serviços públicos de saúde no seu âmbito de atuação.
\end{abstract}

A Constituição de 1988, na área da saúde, de fato, descentralizou o poder decisório. Situação bem diferente ocorreu com a descentralização dos tributos. Os municípios brasileiros, que no período 1964-88 detinham 15\% dos recursos nacionais, após a promulgação da Constituição de 1988 saltaram para 22,75\% (Silva, 2002:106). Apesar do salto, esse percentual não significava que o Brasil estaria, de fato, concedendo recursos à administração local compatíveis com o volume das tarefas delegadas à instância municipal. $\mathrm{Na}$ maioria dos países desenvolvidos, o repasse para os municípios é sempre maior que $30 \%$ dos recursos nacionais, apesar da maior parte desses países serem unitários e não federativos. Nesse aspecto vale lembrar exemplos significativos como o da Suécia que destina $68 \%$ dos recursos tributários para gastos localmente determinados (World Bank, 2001).

Os municípios brasileiros alcançaram com a Constituição de 1988 uma tríplice autonomia: política, administrativa e financeira. Do ponto de vista da técnica legislativa, de fato, os municípios conquistaram plena autonomia política para eleger os poderes Executivo e Legislativo municipais e legislar sobre os temas de âmbito local. A autonomia administrativa obtida permitiu também o pleno poder decisório para o ordenamento dos serviços públicos locais. A autonomia financeira permitiu a implantação de alguns impostos, definição de alíquotas e liberdade significativa para aplicação das rendas municipais cumpridas, obviamente, as determinações da Lei de Responsabilidade Fiscal. É obrigatório lembrar, porém, que mais de $40 \%$ dos 5.506 municípios brasileiros têm menos de 10 mil habitantes e mais da metade não arrecada o suficiente para quitar as despesas dos poderes Executivo e Legislativo locais. Em mais de 2.000 municípios brasileiros não se arrecadam impostos federais por diferentes razões, inclusive pela inexistência de fator gerador (Mendes, 1998). 
Não é possível deslocar o forte espírito de descentralização vigente na Constituição de 1988 do momento histórico de sua elaboração e promulgação. Os excessos centralizadores do período posterior a 1964 geraram fortes pressões descentralizadoras. Os profissionais de saúde, muito mais que os da educação, por exemplo, tinham acumulado um patrimônio de contestação à idéia de centralização e, quando a Constituição de 1988 foi elaborada, isso se transformou em um grupo de pressão organizado. O SUS é o produto mais bem elaborado desse democrático processo de enfrentamento dos excessos da centralização. Do mesmo modo, convém não esquecer que nesse momento, se articulou, também, a reação organizada da burocracia federal, dona de uma eficiente história de centralização de recursos públicos muito anterior aos excessos do período de 1964 a 1988. E o SUS foi a vítima predileta dessa reação organizada da instância burocrática federal.

As decisões operacionais sobre a saúde pública dos brasileiros foram descentralizadas mas o repasse das verbas para efetivar tais decisões não foram. É fato que, a partir de 1993, o governo central conseguiu "reforçar a capacidade de indução e controle das mudanças no funcionamento do sistema de saúde pelo nível federal, a partir dos mecanismos de financiamento" (Levcovitz, 1997, citado por Misoczky, 2003). Apesar das determinações constitucionais, o objetivo do governo central sempre foi o de operar essa política de saúde por meio de atos administrativos federais sustentados, essencialmente, pela realidade do "orçamento autorizativo". A Norma Operacional Básica (NOB) do SUS, de 1993, marca tanto os primeiros passos de uma descentralização administrativa do sistema de saúde, como estabelece formas rígidas de manutenção das estruturas de financiamento em instância federal. Desde os primeiros momentos da implantação do SUS, consolidou-se o exercício da "descentralização tutelada", expressão cunhada ainda no início dos anos 1990 (Viana, 1992).

A Norma Operacional Básica é a portaria do governo federal que define objetivos e diretrizes estratégicas para o processo de descentralização e de relações entre as esferas de governo. Esse dispositivo infralegal possui caráter transitório, podendo ser reeditado ou alterado a qualquer momento. Como o sistema é operado por NOBs "federais" o conceito de descentralização cai em uma espécie de "vácuo decisório" plenamente preenchido pela instância federal porque, enfim, o recurso financeiro, ou melhor a liberação dele, é sempre um ato "de Brasília". A menção no texto de Misocsky (2003) do processo de "esculpir o SUS a golpes de portaria" é bem correta, especialmente porque esse foi um fenômeno que se iniciou desde a edição da primeira NOB, em janeiro de 1991. 
Não há dúvida que a "organização regionalizada e hierarquizada da rede de serviços", como determina a Lei Orgânica da Saúde, exige a prática constante da negociação entre as esferas de governo porque o Brasil é uma federação. No que se refere à política de saúde, as características próprias da ordem federativa brasileira foram utilizadas para acelerar o processo de municipalização do atendimento de saúde. Esse processo ocorreu junto a um fenômeno de impressionante migração urbana. As cidades médias cresceram nos anos 1990, tanto em expansão demográfica quanto em multiplicação de oferta de trabalho, pelas mudanças no mapa de emprego no país (Pochmann, 2001). Além disso, nos grotões do Brasil, o meio rural "misturou-se" a minúsculos núcleos urbanos, com a renda e profissão do indivíduo ainda vinculadas ao campo e sua sobrevivência como cidadão vinculada a paupérrimos núcleos urbanos, provocando dura controvérsia sobre o perfil dessa urbanização (Veiga, 2003). Desde 1988, multiplicaram-se municípios, com o país alcançando 1.406 novas cidades; em dezembro de $2000,98 \%$ do total de municípios brasileiros, de formação recente ou não, aceitaram a tarefa de "gerir" a oferta de saúde, tanto no plano de atenção básica, quanto epidemiológico e até, em certos casos, no atendimento de média complexidade.

O resultado desse processo de municipalização a toque de caixa já foi constatado pelo Censo da Saúde do IBGE de 2000, quando 92\% dos 32.962 estabelecimentos públicos de saúde no país já eram de responsabilidade dos municípios. O mesmo censo mostrou que as prefeituras já arcavam com a gestão de 69\% de hospitais, clínicas e postos de atendimento ambulatorial (Leal, 2000). Como mais da metade dos municípios brasileiros não arrecada sequer o suficiente para quitar as despesas dos poderes Executivo e Legislativo locais não é difícil imaginar tanto o grau de carência operacional que acompanha essa efetiva municipalização do atendimento, quanto o grau de importância da "tutela" do repasse orçamentário federal.

\section{A questão da universalidade}

O processo de municipalização que caracteriza o funcionamento do SUS, desde o início, foi marcado por outra exigência, a da universalidade. A operacionalização dessa exigência foi ainda mais complexa que a da municipalização pelos próprios limites do que chamamos de Estado "anêmico", típico dos anos 1990. O direito à saúde como um exercício universal era um texto legal à espera de uma consolidação na realidade. A crise do Estado brasileiro, "acompanhada da progressiva desativação de equipamentos federais e estaduais na área da saúde, em decorrência da não reposição de servidores e 
sucateamento desses serviços" (Silva, 2002) ampliou a demanda não atendida por saúde no espaço público. A desagregação institucional do sistema público abriu espaço para a criação de um subsistema privado, supletivo, voltado às camadas médias da população e, ao longo do tempo, atendendo também à parcela "privilegiada" das camadas pobres, os "com carteira assinada". As empresas preferiram envolver-se nos custos operacionais do atendimento de saúde de seus funcionários em face da situação real do sistema público que, aliviado dos setores médios e de parte considerável dos trabalhadores do setor formal, abriu espaço para uma plena incorporação dos segmentos sociais mais desprotegidos. Paim (1999) nomeou esse sistema de "SUS para pobre", pois oferece assistência médica simplificada, reduzindo acesso aos procedimentos mais complexos.

A universalização do sistema é, portanto, "excludente", pois afasta as camadas médias e assalariados e também não oferece atendimento de média e alta complexidades compatível com a demanda das camadas mais pobres. A partir daí, o autor acima mencionado identificou quatro sistemas diferentes de SUS: o "para pobre"; o "legal", o "real" e o "democrático". O primeiro SUS pratica a medicina simplificada e o atendimento "possível" e, de fato, atende a todos com as condições que a realidade daquele momento, naquele posto médico, permite. O SUS "legal" está descrito nas leis e nas normas operacionais; já o SUS "real" está marcado pela falta de controle, pelos inacreditáveis "vazamentos" de recursos e por todas as dificuldades de fiscalização conhecidas. O SUS "democrático" pertence ao terreno da vontade de muitos que desejam a reforma sanitária mas, de fato, limita-se a uma "imagem objetiva" (Paim, 1999). Cada um desses SUS integra o sistema que deveria ser "único".

As críticas, mais ou menos acirradas, à operacionalidade do sistema não podem perder de vista as dificuldades orçamentárias enfrentadas pelo Estado brasileiro para implantar a oferta universal de atendimento de saúde. Países com PIBs bem maiores, que o do Brasil, com renda per capita 10 vezes maior enfrentam dificuldades semelhantes (Financial Times, 2004). Por outro lado, é fato que a introdução do projeto SUS ocorreu paralelamente à pressão por centralização decisória na esfera federal e por clara separação operacional entre o subsistema de atenção básica e o de média e alta complexidades. Esta última concepção era defendida pelas agências internacionais de apoio técnico e financeiro (Misoczky, 2003). Essa autora também notou que as NOBs, editadas desde 1991, funcionaram como uma normatização com "implicações importantes para a configuração do mix público e privado e para a eqüidade na implantação e desenvolvimento do SUS".

O alerta de Misoczky quanto ao mix público e privado precisa ser levado em conta, porque atendimento de saúde é "mercado imperfeito". As agências 
internacionais de fomento identificaram com clareza que apenas a solução de mercado era "impossível" na saúde. A lógica de mercado trabalha com demanda elástica; em uma situação de "mercado perfeito", qualquer produto pode aumentar de preço e permanecer no mercado. O consumidor tem a opção de não comprar e o produtor tem a opção de "convencer" o comprador ao consumo (usando ações de marketing), com um preço cada vez maior. O mercado é perfeito porque é livre. Isso é incompatível com o produto saúde. O mercado é imperfeito porque o consumidor não pode "não comprar" o remédio ou o serviço médico que salvará sua vida. O mercado é imperfeito porque o consumidor não tem escolha e o produtor (teoricamente) não consegue convencer o consumidor a comprar o produto saúde, se não está doente. O Estado intervém na oferta de saúde obrigatoriamente porque o mercado é imperfeito. A estratégia operacional do SUS parte dessa premissa. Não é possível tentar criar demanda elástica em saúde, e também não é possível limitar a oferta do produto. As distorções nessas duas premissas forçam desvios brutais de objetivos no mix público/privado, bem apontado por Misoczky. A universalidade do SUS não é compatível com a dinâmica de mercado e, exatamente por isso, a operacionalidade da reforma do sistema não obedeceu parâmetros clássicos da lógica dos "mercados perfeitos". Porém, não há dúvida que o aprimoramento do ambiente SUS depende de inadiável reforma gerencial, o que significa realidade bem diversa.

\section{Outras formas de gerência do ambiente SUS}

Em valores absolutos, os números do SUS são relevantes. Em 2003 o orçamento do sistema alcançou R $\$ 30,05$ bilhões. Esses recursos permitiram, naquele ano, a realização de 1,1 bilhão de procedimentos de atenção básica, 251 milhões de exames laboratoriais, 2,6 milhões de partos, 83 mil cirurgias cardíacas, 23,4 mil transplantes de órgãos. Procedimentos de prevenção epidemiológica e a extensa e eficaz rede de vacinação nacional também são responsabilidade do sistema. Em outubro de 2003, o Ministério da Saúde estimava que os gastos com saúde pública por intermédio do SUS alcançavam pouco mais de R $\$ 200$ ao ano por habitante no país (Sant'anna, 2003). A exigüidade de recursos destinados à saúde está na origem de boa parte dos problemas do SUS. Por outro lado, graves defasagens de padrão gerencial também explicam as crises de eficiência do sistema.

Desde a NOB de 1993, o SUS convive com dois instrumentos de gestão. O primeiro é o que estabelece o subsídio à demanda, por meio de um sistema de pré-pagamento per capita. O segundo mantém o tradicional sistema de 
manutenção do subsídio à oferta por meio da célebre remuneração por produção. A rigor, esses dois instrumentos de gestão estabeleceram uma divisão operacional: no primeiro ficou a responsabilidade com a atenção básica e a média complexidade; no segundo ficou a referência ambulatorial e hospitalar. Na prática, a atenção básica reteve o papel de subsistema de entrada e controle, adotando o sistema inovador de pré-pagamento; já o outro subsistema, que inclui atendimento de maior complexidade e ambulatorial, manteve a tradicional remuneração por serviço prestado.

Na última década esses dois instrumentos de gestão tiveram uma história de relacionamento com a burocracia do Estado e com as formas de repasse orçamentário bem diferente. O subsistema por pré-pagamento foi redimensionado pela NOB de 1996, e foi prioritariamente nesse subsistema que as experiências de municipalização da saúde, corretas ou incorretas, ocorreram. O subsistema de pagamento por produção permanece à espera de atitudes gerenciais renovadoras, entre elas o cartão eletrônico. Apesar de sua importância, a implantação do cartão não avança. Sequer a lógica de mercado, lembrada por Misoczky, para a modernização do sistema de pagamento por serviço prestado, avança, pressionada pela sobrevivência de certas práticas de monopólio na escolha dos prestadores de serviço.

\section{O subsistema de pré-pagamento e a descentralização tutelada}

A NOB/SUS/96, editada em novembro daquele ano, previa duas formas de gestão para o subsistema por pré-pagamento: a gestão plena de atenção básica e a plena do sistema de saúde, que substituiriam todas as disposições anteriores. Para a gestão plena de atenção básica cabia ao município elaborar a programação municipal dos serviços básicos, gerenciar as unidades laboratoriais próprias, prestar ou acompanhar os serviços relacionados à atenção básica e executar as ações básicas de vigilância sanitária e epidemiológica. Era obrigatório comprovar o funcionamento do Conselho Municipal de Saúde, operar o Fundo Municipal de Saúde e ter um Plano Municipal de Saúde. Satisfeitas tais condições, os benefícios alcançados incluíam a obtenção das transferências diretas dos recursos federais ao município, bem como ter as unidades básicas de saúde no território do município, estatais ou privadas, subordinadas à gestão municipal.

À gestão plena do sistema municipal cabia elaborar a programação municipal dos serviços básicos, especializados e hospitalares; gerenciar unidades laboratoriais e hospitalares próprias; garantir prestação de serviço até mesmo aos não-residentes, conforme a programação pactuada e integrada (PPI); exer- 
cer o controle público nos serviços ambulatoriais e hospitalares e as ações de vigilância sanitária e epidemiológica. Os requisitos incluíam o funcionamento do Conselho Municipal de Saúde e do Fundo Municipal de Saúde. As prerrogativas eram a de obter as transferências dos recursos federais e, principalmente, a de ter o conjunto das unidades ambulatoriais especializadas e hospitalares de seu território - até mesmo as privadas contratadas pelo SUS — subordinadas à gestão municipal (Ministério da Saúde, 1996).

O processo de municipalização da saúde se consolida a partir da NOB/ SUS de novembro de 1996, que considera o município o "responsável imediato pelo atendimento das necessidades e demandas de seu povo e das exigências de intervenções saneadoras em seu território". O texto de Silvio Fernandes da Silva (2002) observa que, a partir da NOB/96, o "processo de municipalização expande-se rapidamente" e, em dezembro de 2000, 98\% dos municípios estavam habilitados à gestão plena de atenção básica.

A descentralização da gestão de saúde sofreu, no entanto, uma solução de continuidade com a edição da Norma Operacional de Assistência à Saúde no 01/2001. Essa decisão confirma a observação de que o SUS foi "esculpido a golpes de portaria", pois a NOAS/SUS/01 tinha como objetivo "ampliar as responsabilidades dos municípios na atenção básica mas, efetivamente, aumentar as responsabilidades (e o poder) das secretarias estaduais de saúde na gestão do SUS em relação aos subsistemas de pré-pagamento".

A NOAS/SUS/01 determina que cabe às secretarias estaduais de Saúde elaborar o Plano Diretor de Regionalização para garantir acesso ao cidadão, o mais próximo possível à residência de um "conjunto mínimo de ações e serviços", estabelecendo também o compromisso entre os municípios para o atendimento de referências intermunicipais. O Plano Diretor de Regionalização obedece a alguns pontos básicos como o de "módulos assistenciais", que representam um conjunto de municípios que atuam referenciados a um "municípiosede" que está apto a oferecer um elenco de serviços de média complexidade. Há um município-pólo que atende aos demais do módulo em qualquer nível de atenção. Os módulos constituem regiões e microrregiões de saúde conforme as suas possibilidades de atendimento. A operacionalização da regionalização pertence às secretarias estaduais de Saúde a quem cabe coordenar todas as mudanças (Ministério da Saúde, 2001).

A autonomia municipal na gestão de saúde, obviamente, acaba reduzida com essa forma de regionalização. Quando a ela se soma a centralização real do orçamento da União, essa autonomia se reduz a uma frase eloqüente onde a retórica passa a ocupar quase todo o espaço da realidade. Não há dúvida de que o art. 198 da Constituição Federal é suficientemente preciso quanto às ações e aos serviços de saúde que "integram uma rede regionalizada e hierarquizada e 
constituem um sistema único"; ora, a regionalização e a hierarquização desse sistema avançou, mas a idéia de rede — base de qualquer sistema operacional descentralizado, não só de saúde — avançou muito pouco.

\section{Limites operacionais do conceito de rede}

O processo de implantação do SUS priorizou o conceito de "assistência" (Junqueira, 2000). Não poderia ser diferente, já que a estrutura sobre a qual o novo sistema foi implementado era a do Instituto Nacional de Previdência Social, o INPS. Essa estrutura obedecia modelo que priorizava o hospital como núcleo do atendimento. Desde a sua criação, em 1966, vigorou no INPS o princípio do "convênio" com estabelecimentos privados. Em poucos anos, o modelo gerou resultados expressivos: entre 1969 e 1985 a expansão do número de leitos na rede privada foi de $465 \%$ e, nos dois últimos anos daquele período, $69 \%$ dos recursos do instituto foram repassados para a rede hospitalar privada (Silva, 2002). A reorganização de oferta de serviços de saúde pública proposta pelo SUS não poderia desprezar essa realidade. A visão intra-setorial e a manutenção de perspectiva assistencialista, nos primeiros momentos do SUS, foi exigência de sobrevivência da proposta, em "habitat hostil".

Ao longo da década de 1990, no entanto, foi possível iniciar um processo de construção de estrutura alternativa à lógica hierarquizada, marcada por decisões centralizadas, típicas do "modelo INPS". A arma mais eficiente para enfrentar a extrema verticalização de estruturas decisórias é sempre a idéia de rede que privilegia interações organizacionais. O texto constitucional prioriza o conceito de rede (art. 198) e a operacionalidade da política pública que norteou a implantação do SUS optou por "atividades interorganizacionais", porque, enfim, como alertou Junqueira (2000), o sistema é "parte de um projeto maior de sociedade solidária". E o conceito de rede é essencial para que atividades interorganizacionais envolvam, de fato, diferentes atores nas políticas públicas.

$\mathrm{O}$ aspecto mais importante da atividade interorganizacional nãoverticalizada é o estabelecimento de conexões entre a oferta de um bem ou serviço público e a demanda mais necessitada desse serviço. A operação em rede não significa apenas incentivar a conexão, bem definida do ponto de vista federativo, entre os poderes federal, estadual e municipal; também não implica apenas definir os precisos limites das tarefas, sem invasões ou "conflitos de fronteiras" entre os poderes de Estado. Insistimos na perspectiva de McGuire 
(2002) de que rede não é apenas padrão de interação, mas a forma pela qual o serviço público é "planejado, concebido, produzido e oferecido à população".

$O$ processo que permite o passo além da simples interação entre as instâncias de poder, ou entre órgãos geograficamente dispersos, é o que entende o conceito de rede como "uma linguagem de vínculos das relações sociais entre organizações". (Junqueira, 2000). O "xis" da questão está em como convencer os diferentes atores das diferentes organizações a falarem a mesma "linguagem", suficientemente eficaz para gerar "vínculos". Misoczky (2003) retoma o mesmo desafio lembrando a posição de Fleury (2002) que afirma que um dos grandes desafios da organização em rede está em estabelecer "modalidades de gerências" capazes de articular objetivos comuns. A visão teórica de McGuire (2002) identificou "comportamentos" essenciais para a gerência em rede, baseados em um tripé: primeiro, a "descoberta" de pessoas e recursos necessários para alcançar os objetivos da rede; depois, criar "compromissos comuns" entre os integrantes da rede; e, por último, "desenvolver um ambiente" que incentive a integração. A identificação desses comportamentos é, de fato, a base de um cotidiano operacional "em rede", mas é insuficiente para estabelecer "modalidades de gerência" aptas a exercerem objetivos integrados. A questão essencial aí está na incorporação de diferentes atores no processo decisório das políticas de saúde. Tal incorporação depende da forma de planejamento e participação na gestão de saúde.

A interação entre o planejamento e a participação nunca foi processo de fácil condução. A implantação do SUS demonstrou que o conceito de "gestão participativa" foi capaz de dar conta, no contexto operacional, da inclusão de novos atores no "ambiente" da saúde pública. É um fato que a instituição dos conselhos municipais e locais de saúde representou uma estratégia essencial para promover participação na gestão. A fiscalização do serviço prestado pelos agentes locais democratizou até decisões sobre aplicação de recursos e efetivou a descentralização possível alcançada pelo SUS. Porém, esse processo foi insuficiente para incentivar a participação no planejamento (e nas decisões) da macropolítica de saúde pública. A incorporação de novos atores no efetivo processo decisório em saúde depende da capacidade sistêmica de assimilar o conceito de "planejamento participativo".

Desde o início da década de 1990 o planejamento em saúde é pensado a partir de três etapas: a normativa, a estratégica e a da estratégia vinculada ao planejamento, como proposto por Chorny (1990). O planejamento normativo, analisado por Silvio Fernandes da Silva (2002), foi muito influenciado pelo predomínio do "racionalismo" dos anos 1960 em que a decisão técnica bem fundamentada, independente do contexto social em que era aplicada, era suficiente para promover desenvolvimento, especialmente em saúde pública. 
Em meados dos anos 1970, além de "normas", o planejamento passou a reconhecer a existência de "conflitos no contexto social" e ganhou uma perspectiva estratégica por aceitar novos "integrantes" (como as características da população local), além da ciência no processo de planejamento. Decisões de âmbito político também tiveram influência reconhecida no planejamento em saúde pública. A real vinculação da estratégia (no sentido da multiplicidade de atores que interferem em uma decisão de saúde pública) ao planejamento só foi alcançada em um terceiro momento, já nos anos 1990, quando se distinguiu, no ato de planejar, a importância de métodos e técnicas assim como dos limites da aplicação de certas decisões em contextos sociais específicos. A rigor, a resposta ao célebre "o que fazer" em saúde pública ganhou uma dose de humildade em relação à certa visão que julgava infalível determinados procedimentos, apenas porque eram cientificamente comprovados.

O mix do planejamento em saúde com as possibilidades políticas e com os limites da "vontade" da população-alvo, aceitando as diferenças na "visão de mundo" de cada um dos atores envolvidos, constitui processo de "planejamento participativo". Esse salto de qualidade no planejamento institucional o SUS ainda não obteve.

\section{Fluxos de recursos e novos padrões operacionais}

O processo de estabelecimento de modalidades de gerência que construam uma "linguagem de vínculos", que permita a gestão em rede do SUS, depende da superação de alguns "gargalos" operacionais e financeiros do sistema. Entre os gargalos operacionais é preciso lembrar o difícil percurso do "cartão eletrônico" no SUS; desde a experiência em São José dos Campos, no interior de São Paulo, iniciada em 2000, o cartão eletrônico que permitiria a plena informatização dos serviços prestados aos usuários do SUS, é uma promessa não cumprida. Em junho de 2001, a partir dos resultados obtidos na experiência de São José dos Campos, onde 51 unidades de saúde pública foram integradas em uma mesma base de dados, o Ministério da Saúde prometeu integração semelhante, em um projeto piloto, das unidades de saúde de 44 municípios brasileiros. Nessa mesma oportunidade, o ministério reiterou à imprensa que "em um ano" 2 mil municípios com mais de 15 mil habitantes estariam integrados na rede eletrônica do SUS (O Estado de S. Paulo, 2002). Há notícias de experiências semelhantes à de São José dos Campos, ao longo de 2003, em alguns estados do Sudeste, mas não há confirmação de uma ampliação da base de dados integrando mais de um município. 
Em 2001, quando o Ministério da Saúde apresentou plano de expansão do cartão eletrônico, o sistema seria financiado pelo repasse de recursos do Fundo de Universalização dos Serviços de Telecomunicações (Fust), formado por $1 \%$ da receita das operadoras de telefonia fixa no país que começou a ser recolhido em janeiro de 2001. Os recursos seriam usados na compra e manutenção de linhas de telefone e demais equipamentos necessários à transmissão de dados dos postos de saúde integrados à rede. A contribuição do Fust foi recolhida pelas empresas mas não chegou ao orçamento do Ministério da Saúde. O recurso que permitiria a implantação do cartão eletrônico era uma verba "carimbada" mas, apesar dessa garantia, não alcançou a receita da saúde.

Destino diferente poderá ter a proposta, de junho de 2004, referente à revisão da Emenda Constitucional no 29 , que determinou orçamento mínimo vinculado para a saúde nas instâncias municipal, estadual e federal. O movimento de adesão dos prefeitos aos planos de atenção básica se deveu à segurança que a emenda dava aos prefeitos quanto à perenidade no fluxo de recursos. As autoridades municipais viram nessa determinação constitucional a garantia para aceitar a "descentralização" sem o fundado receio de que "no próximo ano" ocorresse retração brusca no repasse de verbas do orçamento nacional, deixando-as com as responsabilidades da saúde básica no plano municipal e sem os recursos da esfera federal. Se ocorrer a revisão da Emenda Constitucional no 29, o prejuízo maior incidirá sobre essa reserva de credibilidade que impulsiona a autoridade municipal a colaborar com a "descentralização" do sistema de saúde

A análise sobre a década e meia de implantação do SUS, portanto, não pode ser deslocada nem de seus aspectos intra-setoriais - sejam as crises gerenciais, sejam os métodos de planejamento e participação - nem da lógica perversa que cerca a mínima garantia de perenidade do fluxo de recursos para a saúde pública.

\section{Referências bibliográficas}

A INFORMATIZAÇÃO do SUS. O Estado de S. Paulo, 2 jun. 2002. Editorial.

BUENO, W. S.; MERHY, E. E. Os equívocos da NOB 96: uma proposta em sintonia com os projetos neoliberalizantes? Disponível em: <www.datasus.gov.br/cns>.

CHORNY, A. H. El enfoque estratégico para el desarrollo de recursos humanos. Educ. Med. Salud, v. 24, n. 1, 1990.

DIAMANTE, F. Metade da frota de carros de São Paulo é fantasma. O Estado de S. Paulo, 27 abr. 2004. 
FINANCIAL TIMES. The rising cost of healthcare - international comparison can help restrain it, $19 / 20$ jun. 2004. Editorial.

FLEURY, S. El desafio de la gestion de las redes de políticas. Disponível em: < www.iigov.org/ revista/12/12-09.pdf >.

JUNQUEIRA, L. P. Intersetorialidade, transetorialidade e redes sociais na saúde. Revista de Administração Pública, v. 34, n. 6, 2000.

LEAL, L. Censo revela queda na oferta de leito hospitalar. O Estado de S. Paulo, 7 out. 2000.

LEVCOVITZ, E. Transição versus consolidação: o dilema estratégico da construção do SUS. Um estudo sobre as reformas da política nacional de saúde. 1997. Tese (Doutorado) Universidade do Estado do Rio de Janeiro, Instituto de Medicina Social, Rio de Janeiro, 1997.

McGUIRE, M. Managing networks: propositions on what managers do and why they do it. Public Administration Review, v. 62, n. 5, 2002.

MENDES, E. V. A organização da saúde no nível local. São Paulo: Hucitec, 1998.

MINAYO, M. C. S. Sobre a complexidade de implementação do SUS. Prefácio. In: SILVA, F. S. Municipalização da saúde e poder local: sujeitos, atores e políticas. São Paulo: Hucitec, 2001.

MINISTÉRIO DA SAÚDE. Portaria no 2.203. Diário Oficial da União, 6 nov. 1996.

. Situação atual do processo de habilitação. Disponível em: <www.saude.gov.br/ decen/habilita.htm>. Acesso em: 20 set. 2000.

. Portaria no 95. Diário Oficial da União, 26 jan. 2001.

MISOCZKY, M. C. Redes e hierarquias: uma reflexão sobre arranjos de gestão na busca da eqüidade em saúde. Revista de Administração Pública, v. 37, n. 2, 2003.

PAIM, J. S. Políticas de descentralização e atenção primária à saúde. In: ROUQUARYROL M. A.; ALMEIDA, F. N. Epidemiologia \& saúde. Rio de Janeiro: Medsi, 1999.

POCHMANN, M. O trabalho sob fogo cruzado. São Paulo: Contexto, 2001.

SANT'ANNA, L. Sofisticação e precariedade convivem no SUS. O Estado de S. Paulo, 29 jun. 2003.

SILVA, S. Fernandes da. Municipalização da saúde e poder local: sujeitos atores e políticas. São Paulo: Hucitec, 2001. 
VEIGA, J. E. Cidades imaginárias: o Brasil é menos urbano do que se calcula. São Paulo: Edusp, 2003.

VIANA, S. M. A descentralização tutelada. Saúde em Debate, n. 35, 1992.

WORLD BANK. World development indicators. Washington: The International Bank for Reconstruction and Development, 2001. 